\title{
Radical enhancement as a moral status de-enhancer
}

\author{
Jesse Gray ${ }^{1}$ D \\ Published online: 30 July 2020 \\ (c) Monash University 2020
}

\begin{abstract}
Nicholas Agar, Jeff McMahan and Allen Buchanan have all expressed concerns about enhancing humans far outside the species-typical range. They argue radically enhanced beings will be entitled to greater and more beneficial treatment through an enhanced moral status, or a stronger claim to basic rights. I challenge these claims by first arguing that emerging technologies will likely give the enhanced direct control over their mental states. The lack of control we currently exhibit over our mental lives greatly contributes to our sense of vulnerability. I then argue moral status should be viewed in terms of vulnerability. The enhanced will slowly gain the ability to command their mental states, reducing their vulnerability. These radically enhanced beings will have greater capacities, and possibly an inner life more valuable than our own. They will also be less vulnerable, and as a result, their moral status will be subordinate to our own.
\end{abstract}

Keywords Mental states $\cdot$ Moral status $\cdot$ Radical enhancement $\cdot$ Rights · Vulnerability

\section{Radical enhancement as a moral status de-enhancer}

Radical enhancement-those enhancements that bring our capacities and abilities reatly outside species-typical functioning-have worried many. Nicholas Agar has argued that radically enhanced beings will have a moral status that exceeds our own (2014). Jeff McMahan has voiced a similar concern, focusing on our violability (2009), while Allen Buchanan worries the radically enhanced will have stronger interests than mere persons (2009). I will argue these concerns are misguided, as these novel beings will have a moral status subordinate to our own.

This paper is broken into six sections. The first section will be spent getting clear on the views of Agar, McMahan and Buchanan. In Section Two I will motivate a plausible conception of the radically enhanced. Section Three will be spent testing

Jesse Gray

Jesse.gray2@colostate.edu

1 Colorado State University, 243 Eddy Hall, Fort Collins, CO 80526, USA 
the conceptions of moral status offered by Agar, McMahan and Buchanan against my own conception-moral status as vulnerability. Section Four will be spent arguing for a narrow conception of vulnerability and its theoretical relation to moral status. In section Five I argue that cognitive enhancements are a morally desirable thing. The final section is reserved for objections.

\subsection{Enhancement and moral status}

Our abilities can be enhanced along many dimensions. Enhancing our physical abilities may include strength, stamina and vision, all of which are important for athletics and in daily life. We can mitigate muscle tremors, enhancing our ability to create art and perform surgery. Or we can enhance our emotional and cognitive capacities, those things that constitute our inner life. These cognitive and emotional enhancements may take the form of intelligence and memory, or those elements that make our inner life worth having, love, joy and empathy to name a few. It may be possible to enhance moral behavior, these moral disposition enhancements can make more moral behavior more likely (Douglas 2008). We may even enhance moral status directly. Moral status enhancement may arise from the development of a new capacity, or perhaps augmenting capacities such as rationality and empathy may be sufficient to raise moral status. A variety of methods can be employed to make these enhancements a reality. Biochemical interventions, such as performance enhancing drugs are one option. Genetic interventions are becoming much more likely with the targeted approach of CRISPR-Cas9. Environmental enhancements we are all familiar with, these include legal and educational institutions, as well as societal norms. While the radically enhanced will most likely be enhanced along every dimension mentioned and utilize several methods, the most pertinent to this discussion are those enhancements that constitute our inner life. In Section Two I will focus most closely on cognitive and moral (disposition and status) enhancement. But first, I want to get clear on several views of moral status

Nicholas Agar takes no issue with the enhancements mentioned above, as long as they are moderate enhancements-those enhancements that strengthen our capacities and abilities within species-typical functioning. Agar is concerned that enhancing outside the species-typical range will create post-persons-beings with greater moral status than mere-persons (Agar 2014, p. 157). If this is right, then it seems we mere persons may lose many of the rights and privileges we have grown accustom to. The radically enhanced may edge us out of cooperating in civil society, they may act paternalistically toward us undermining our autonomy, or they may even use us as model organisms in research, in much the same way we abuse a variety of nonhuman animals

Agar focuses on direct moral status enhancements. Enhancing non-human animals with capacities sufficient for personhood would be one way to directly enhance moral status. For Agar a moral status enhancer "increases a being's entitlement to certain forms of beneficial treatment and reduces it's eligibility for certain types of harmful treatment" (Agar 2014, pp. 158-159). So moral status is: 
MS A being's entitlement to certain forms of beneficial treatment, and reduced eligibility for certain forms of harmful treatment

This is an intuitive notion of moral status, but it remains unclear why we should think post-persons could experience the sort of moral status boost non-human animals have the potential to experience through radical enhancement

Two key elements of Agar's argument are: (1) a distinction between weak and strong thresholds, and (2) an induction from everyday observation. Strong thresholds for moral status are insensitive to the modification or addition of capacities. There will be no difference between persons and post-persons no matter the degree or type of enhancement. Weak thresholds are far more sensitive. Post-persons, given significant enough changes will have some feature(s) that will make a positive difference to moral status (Agar 2014, p. 162). Agar favors weak thresholds, but only speaks minimally in support of them. To aid his account I will turn to the work of Stan Husi. Husi argues against strong thresholds (and moral equality amongst mere persons ${ }^{1}$ ). One issue lies in our ability to transform scalar properties into binary ones. For example, rationality is clearly a scalar property that admits of degrees. We can be more and less rational within the species-typical range, and there are a multitude of ways to increase or decrease rationality outside the species-typical range. Figuring out what category, or threshold one is in, just becomes a matter of math. We impose an asymmetry on the math that Husi finds implausible. Take any property relevant to moral status $X,(X-n)$ makes a huge difference to moral status, removing one from a higher threshold. But adding to the relevant property $\mathrm{X}$, $(\mathrm{X}+\mathrm{n})$ makes no difference. Compelling reasons are needed to justify this asymmetry, and Husi finds the asymmetry too implausible to be taken seriously (Husi 2017, pp. 391-92). Weak thresholds offer a plausible alternative to the more commonplace strong threshold view

Agar's second move is to note the well-established gradient of moral concern that already exists. Rocks are sacrificed before non-human animals, and non-human animals sacrificed before persons. Continuing the pattern would suggest that mere persons are sacrificed before post-persons. One thing to note is that it would be a very convenient fact that persons occupy the highest moral status category or tier. Agar's point is much stronger, he argues that if moral statuses higher than personhood exist, and we are confronted with these beings directly, we will be unable to understand and recognize why they have greater status (Agar 2014, pp. 174, 78-80). The reason we don't continue the inductive move is a limitation of our creative and intellectual powers, rather than a feature of the world. These two points don't establish that higher statuses than personhood exist, but they provide enough justification to take the idea seriously

\footnotetext{
${ }^{1}$ Husi's issue is with the conceptual framework of egalitarian principles, primarily threshold accounts. $\mathrm{He}$ is very clear that prejudices of the past and present are deplorable. Even though he finds threshold accounts unjustifiable, this in no way undermines our obligations to treat others with full respect.
} 
A second view on moral status comes from Jeff McMahan, who also finds it plausible that higher statuses than personhood may exist. For McMahan, supra-persons ${ }^{2}$ may enter this uncharted territory. Supra-persons are beings whose psychological capacities exceed our capacities, by more than our psychological capacities exceed those of non-human animals (McMahan 2009, p. 600). As increasing our psychological capacities alone might not be enough to alter moral status, McMahan offers the possibility that a new emergent property may grant access to a higher moral status threshold. The difference between mere and post-persons is the degree to which each is inviolable. In normal circumstances no human being can be sacrificed for the benefit of another human being. But when the numbers are large enough, it becomes permissible to sacrifice one innocent person to save the lives of the many. Inviolability isn't equal across all beings as non-human animals have a lower degree of inviolability, as they are readily sacrificed for food, clothing and research (McMahan 2009, pp. 599-601). This second conception of moral status is: moral status as inviolability or (MSI). MSI states:

MSI The degree to which one human being can be sacrificed for the benefit of another human being

If this is right, then a single supra-person can only be sacrificed in the event that their life will save the lives of numerous mere persons. Conversely several mere persons could be sacrificed for the benefit of a single supra-person. I challenge this in section III and argue that supra-persons could be sacrificed before mere persons.

In contrast to Agar and McMahan, Allen Buchanan is highly skeptical of higher moral statuses. One reason is no positive account of the radically enhanced has been given. Without an idea of what enhancements will provide for greater moral status, the concern of beings with greater moral status can be put on hold (Buchanan2009, p. 354). A deeper reason is what Buchanan calls the Moral Equality Assumption (MEA). MEA holds that all beings who possess sufficient attributes for personhood have the same moral status (p. 347). Buchanan favors a strong threshold account, grounded in Kantian respect and the capacity for mutual accountability. For Buchanan, strong thresholds and the MEA better match our intuitions about why beings with certain capacities deserve equal respect, and why increasing those capacities doesn't alter this base level of respect. This is contrasted with an interestbased view, which he attributes to Utilitarians. Buchanan views interest-based views as discarding moral status thresholds all together and puts interests along a single continuum. The problem with this view is that it is easy to classify different interests along a spectrum, but it is hard to draw a sharp line between interests. For example, it becomes difficult to draw a sharp line between humans and non-human animals (Buchanan 2009, pp. 360-361). As we intuitively draw this line, we should prefer strong thresholds, over interest-based accounts. Further, if we treat all properties as if they were scalar properties, we might note the great variation in capacities and

\footnotetext{
2 Post-Persons, supra-persons and the radically enhanced are synonymous. I will use them interchangeably for stylistic reasons. I hope the reader won't find this terribly confusing.
} 
talents that already exist. It may be tempting to lower or raise the status of some humans and given our history that may be too much to accept

Buchanan's chief concern is not about greater moral status (since there is unlikely to be higher ones), it is about what happens if competing interests emerge, ones that confer different rights on the enhanced and unenhanced. Post-persons may become enhanced cooperators, engaging in civic life in ways mere persons are unsuited for. Post-persons may act paternalistically toward us in the same way we act paternalistically towards the severely disabled (with the intent of protecting them), or they may exclude mere persons as they lack the capacity to cooperate in a meaningful way (Buchanan 2009, pp. 373-375). Buchanan uses the analogy of a card game. It is permissible to minimize participation between Go Fish players (mere persons) and Bridge players (post-persons) since Go Fish players can't cooperate, interact with, or make a meaningful contribution to the game of Bridge. The interests of the Bridge players supersede that of Go Fish players. These conflicting interests may be so great that the radically enhanced enjoy a richer set of rights, guaranteeing that their interests take priority, while the unenhanced enjoy a simpler basic set of rights. As their moral status is the same, a third concern is that of conflicting interests or (CI)

(CI) All agents share an equal moral status, but not equal interests. The enhanced will have a stronger claim (or right) to have their interests fulfilled

Three views of moral status have just been offered. Two items still need addressing. First, we need a conception of what a radically enhanced being will be like. In the next section I will add to McMahan's account of supra-persons. Second, we need to know the practical impact of the theoretical principles put forward earlier. In section Three I argue that the implications of MS, MSI and CI previously discussed are untenable and should be abandoned

\section{Radical enhancement}

As mentioned previously, the radically enhanced will likely experience a wide array of enhancements utilizing an array of technologies. While super-intelligence and athletic prowess are likely features of post-persons, what is often overlooked is some ability to modulate their inner life. Mere persons do this routinely, albeit in an indirect fashion. Music, mediation or a serene walk are readily available tools to attenuate stress and anxiety. To engage our empathy we may focus on people who look like us or focus on events that contain small numbers of people, as it is impossible to empathize with millions at once (Bloom 2018, pp. 31-34). To deal with the stressors of war soldiers often resort to telling "cold jokes," jokes that dehumanize enemy combatants making it easier to kill and torture them (Glover 1999, pp. 36-37), matching our psychology, which may be geared towards imbuing essential properties on others (Smith 2012, pp. 32-34, 100-101). Most of our day is spent trying to control our mental states, for better or worse. More than two thousand years ago Sextus argued for skepticism as a form of medicine that would allow one to suspend judgment and enter ataraxia (Empiricus 1996). Buddhists focused on meditation as 
the mechanism to ameliorate suffering (De-Bary and Bloom 2000, pp. 435-440). In what follows I will discuss current technology that will give us greater access and control over our inner lives. I then speculate that increasing technology could give us the means to directly control our mental states. Direct mental state control will make the indirect tools of mere persons obsolete.

Deep brain stimulation (DBS) involves implanting electrodes in the brain to treat psychiatric and movement disorders. This technique is an improvement on earlier tissue removal surgeries of as it allows for greater control (the ability to manipulate the stimulus) and is reversible as the implants can be removed. Currently only those patients who are resistant to traditional therapies are considered for DBS devices. DBS has shown success as a treatment for depression, anxiety, OCD, Tourette's syndrome, Parkinson's, anorexia, addiction, PTSD and aggressive behavior. One longterm heroin patient even reported feeling decreases and increases of heroin cravings in response to different stimulation settings (Cleary et al. 2015). This technology can modulate our inner life and may one day be used outside of therapeutic contexts to enhance moods and curb unwanted behaviors such as addiction and aggression. DBS is still in its infancy, and not without substantial risks, but can give insights into how the radically enhanced may one day function.

Optogenetics is similar to DBS in its invasive nature but differs mechanistically as it uses light to stimulate neurons as opposed to electricity. Opsins are light sensitive membrane proteins. These proteins react to light in specific wavelengths and constitute the first step in our visual pathway. With the aid of genetic technologies, opsins can be expressed in the brain, and in the presence of light can stimulate neurons rapidly in real time. This can allow for a more targeted approach than DBS as the optic fibers inserted in the brain can emit different wave lengths of light and only stimulate specific target cells (Aravanis et al. 2007). This technology can adjust the focus from broad adjustments (adjusting neurotransmitter level) to the fine-grained approach of targeting a circuit (Deisseroth 2011). Optogenetics has been shown to modify both feeding and predatory behavior in mice. ${ }^{3}$

Brain-Computer Interface (BCI) began development in the late 1970's. Non-invasive methods such as EEG have been used to move mouse cursors (Wolpaw and Mcfarland 2004; McFarland et al. 1997), while the more invasive sensor implantation has been shown effective in cursor control and manipulation of prosthetic hands and robotic arms ${ }^{4}$ (Hochberg et al. 2006). The tasks being performed are still rudimentary, and able-bodied persons would find the technology cumbersome. But it is readily conceivable that one day we will use this sort of technology to operate our phones and computers, and it is not a far leap from there to imagine it can be used to help modulate our inner lives.

\footnotetext{
${ }_{3}$ A video of mice feeding behavior can be found at: https://neurocomplimenter.blogspot.com/2013/09/ While a video of predatory behavior can be found at: https://www.youtube.com/watch?v=FlGbznBmx8 M.

${ }^{4}$ Videos of cursor manipulation (opening emails, drawing circles), gameplay (pong), and manipulating prosthetics are available in the supplementary information section of this paper available on Nature's website.
} 
If post-persons are to command their inner lives, DBS seems to be a poor option. Its mode of delivery is too imprecise to give the sort of control I envision. However, the research gleamed from this technology will be invaluable in our understanding of the effects of direct neural intervention. ${ }^{5}$ Optogenetics is a more powerful tool, but is a long way off in humans, for practical and ethical reasons. Suppose we surpass these hurdles, why limit the use of a system like this to treat depression, OCD, or addictive behaviors? ${ }^{6}$ Why not incorporate fiber optics throughout the entire brain? Doing so would give the ability to enjoy the mental benefits of a long walk, from the comfort of your couch. The brain states would be identical in each case. Modulating our inner lives would be a daunting task for most users, but most of the work will be done by a central computer, that will learn a specific brain and set presets for certain behaviors. The user then will be able to increase or decrease the stimulation based on need. These states will map the ones we routinely experience. Special education teachers may bookmark a calm or patient setting, enhancing their ability to engage with and instruct their students. Athletes may opt to feel stimulated or enlivened when training and competing, enhancing their ability to stick to their daily regiments. Our most intimate mental states, our feelings of passion, lust and love can be modulated. This technology could be used to better match our partners emotional state or to aid in leaving a destructive relationship. ${ }^{7}$

This technology could be integrated seamlessly into our lives. Optogenetic fibers could be controlled by a small computer interface connected to a smartwatch. BCI could allow the user to manipulate this device with their mind, and in a matter of seconds select the preset for the mood they want to be in. The user would then be free to make minor adjustments, increasing or decreasing the stimulus for greater comfort. For those who may find this unsettling, is it really that much different from consuming alcohol after a stressful day at work? Or is it far different than drinking a glass of wine on a first date? My intuition is that it is not. ${ }^{8,9}$

One last enhancement focuses on pain diminution. Since optogenetics can play an inhibitory role, it seems plausible that it could be used to inhibit pain. This would be one way to tailor and dilute our response to painful stimuli. A simpler approach would be to alter the pain nerves themselves. Voltage gated sodium channels $\left(\mathrm{Na}_{\mathrm{v}}\right)$ play a role in pain signaling and are the target of research for new and less addictive analgesics (Offord 2017). $\mathrm{Na}_{\mathrm{v}} 1.7$ has garnered particular interest, as mutations have been identified that both greatly increase and reduce pain, while a complete

\footnotetext{
5 Future research on DBS greatly outweighs that of optogenetics as measured by upcoming clinical trials. These can be viewed at https://www.clinicaltrials.gov

6 Those that endorse the treatment-enhancement distinction will offer reasons not to enhance. I set this issue aside, as it is outside the scope of this paper.

7 Some have argued that modulating our love lives is a morally desirable thing. For an extensive argument on this with practical tools in mind see Love Drugs (Earp and Savulescu 2020).

${ }^{8}$ As the ethics of enhancing are outside the scope of my argument, I will leave this point hanging. For those interested in exploring this point further see Neuroethics (2007) by Neil Levy. He argues for parity between traditional and technological methods of intervention.

9 Andy Clark has argued that we are natural born cyborgs (extended mind hypothesis), and that we are built to integrate technology into us. For numerous examples of how we naturally incorporate technology into our daily lives see Natural Born Cyborgs (Clark 2003).
} 
$\mathrm{Na}_{\mathrm{v}} 1.7$ knockout is non-lethal in humans (Dib-Hajj et al. 2010). It seems unlikely that evolution selected for an optimal level of pain tolerance and our experience of it, but rather, only selected for the right amount to aid in survival and reproduction. Given that we live in a far different environment than our ancestors, it may be appropriate to alter our nociceptors themselves. The goal would not be the elimination of pain, but to dampen it. For example, reducing $\mathrm{Na}_{\mathrm{v}} 1.7$ expression might slightly raise our pain threshold, so that more of a painful stimulus is needed to evoke the pain response.

At this point, the difference between current technology and my account of the radically enhanced is magical. In a discussion on AI, Nick Bostrom has given several reasons to be weary of the prospects for technologies like DBS and BCI, and the timeframe they will be implemented. Several complications may occur which include infection from surgery and stimulating neural tissue outside the target zone. Additionally we have only seen limited success in therapeutic settings, and none in enhancement. It is far easier to bring someone back to baseline, than to improve their capacities. Our brains are finite machines with limited computing power. Adding chips to the brain may do little to aid our thinking, if the brain can only process information so fast (Bostrom 2014, pp. 63-67). Finally, much of the benefits these technologies afford could be done far cheaper, and without the risks associated with enhancement. Healthy skepticism is in order and warranted for the technologies I describe.

DBS, BCI and optogenetics are all key technologies that one day could be incorporated into the enhanced. Other technologies, such as modifying cellular biology could be used to better match our biology to our environment. While these technologies are a long way off from implementation for enhancement, they provide a guide to what the enhanced will be like. This section has been spent giving a plausible conception of how technology could be integrated to create the enhanced. There is room for caution and skepticism as the technology is still in its infancy. The point to keep in mind is that the enhanced may one day exhibit direct mental state control, and these beings should be kept in mind in the next section where I will test them against mere persons.

\section{Altering moral status-two test cases}

Recall Agar's view of moral status, MS, a being's entitlement to beneficial treatment and reduced eligibility to harmful treatment. This conception of moral status will be tested in a hypothetical organ donation case.

\subsection{Hospital}

Imagine an ideal moral agent in need of an organ transplant. Unfortunately the patient is too ill to be moved, and there are no viable donors in the area. Two neighboring hospitals have volunteers to donate and are able to excise the organ. Hospital A is fully modernized offering every amenity, including anesthesia and analgesics. 
Hospital B, while modernized and safe, doesn't believe in modern anesthetics or pain relievers. In all other respects, Hospital B is identical to Hospital A. Assuming there is some moral reason to donate an organ to this agent, although not a strong enough reason to force any agent to donate, should the organ be procured from Hospital A or Hospital B?

Intuitively, Hospital A is the wiser choice. Much of the pain can be mitigated or outright eliminated, and the donor is far less likely to experience any trauma from either thinking about the upcoming surgery, or from actually undergoing the surgery while awake and alert. Hospital B can provide the same outcome as Hospital A (one organ to a patient in need), but it is far riskier, more painful, and offers no additional benefit to that of Hospital A. We can begin to imagine Hospital A represents a postperson and hospital B represents a mere person. Mere persons have some limited techniques to mitigate pain and distress. During the operation they might try to regulate breathing or squeeze the hand of a close friend who has come for emotional support. Outside the procedure they may find external distractions like books, movies or music to avert their attention from the upcoming surgery. Post-Persons on the other hand will have more direct control. Prior to the procedure they may directly lower their anxiety levels or imbue themselves with a general sense of peace about the surgery. During surgery, post-persons may exercise some of the inhibitory control of optogenetics and reduce their pain or outright block it from reaching conscious awareness. Assuming we have some moral reason to mitigate or prevent physical and psychological pain in others, then we have some reason to prefer the post-person in the organ donation case. Since both mere persons and post-persons have a moral reason to donate (for the benefit of an ideal moral agent), post-persons have an additional reason that mere persons lack (reduced physical pain and psychological distress). Since we have an additional reason to prefer post-persons, they should be preferred in this case. This provides some reason to think that we should reject Agar's claim that the enhanced will enjoy a greater status than ordinary humans.

What if we exclude hospital B from the scenario, and imagine a post and mere person in Hospital A? In this case who has greater reason to donate an organ? ${ }^{10}$ The prior reasoning suggests that there would be equal reason to donate between mere and post-persons. I think this is a mistake as mere persons are far more vulnerable, and so, along many more dimensions than post-persons. I will say more about vulnerability in what follows and greatly elaborate on it in section four.

\subsection{The sinking ship}

Hospital was a case of simple transplantation, but what happens in the event of an emergency, where it is guaranteed someone will die? McMahan worries mere persons will be more violable than post-persons (McMahan 2009, p. 601). Recall, MSI posits the enhanced will have greater inviolability than mere persons. One such real life, albeit modified case is the sinking of the titanic. On McMahan's proposal the

10 Thanks to Moti Gorin for bringing this scenario to my attention. 
enhanced would be first on the life rafts. But for reasons similar to that of Hospital, I think they should go last. One reason mere persons will have priority is their sheer vulnerability. Their susceptibility to the fear of drowning and the pain of the cold frigid water, are among the reasons we think it impermissible to throw someone in the water. The enhanced, although incapable of surviving long periods in the cold, may lose out on all the pain of the ice water, and experience no fear of drowning or loss of life. If direct mental state control is taken into account, then we have some reason to think MSI will not dictate the enhanced board first, primarily, the enhanced will miss out on the pain and torment of drowning. Further, we may think of priority in terms of fair innings, where those that haven't had the opportunity to experience a full life are given priority in life and death situation (Harris 1985, pp. 90-94). As the enhanced will have greater capacities, they will have had a better opportunity to experience a fuller range of life, in a shorter period of time. Even though they may be the same age, they have had more "innings" to play in the game of life, due to the fact that their cognitive capacities are greater than ours, by as much as ours are greater than non-human animals. These cognitive enhancements and novel forms of mental state control will make post-persons less vulnerable to the harms that plague our lives. I propose we view moral status in terms of our vulnerability:

MSV Moral status as vulnerability. The greater a being's susceptibility to harm (mental or physical), the greater the protections that are afforded, and hence, the greater an agent's moral status.

We need not completely abandon MSI as it does tell us that we are not items that can be readily sacrificed. The enhanced should not be harmed or in this case be thrown overboard on a whim, as they have a great degree of inviolability, they just have less of this inviolability conferring property than mere persons possess. The criterion to determine violability should be an agent's vulnerability.

\subsection{MSV and conflicting interests}

How does MSV compare to mere interests, will it produce similar results against CI? As we saw Buchanan has expressed concerns about enhanced cooperators edging simple cooperators out of the dominant cooperative framework. ${ }^{11}$ Recall that CI states the enhanced will have a different set of interests, and a richer set of rights guaranteeing their interests take priority. One common interest between mere and post-persons will be exhibiting autonomy, contributing to society and a general feeling that these contributions have a sense of purpose and meaning. Whose interest do we keep in mind, the simple or enhanced cooperator? As the enhanced have greater

\footnotetext{
11 Robert Sparrow raises a stronger concern. Enhancements may proceed so quickly that those born just a few years later will render those just a few years older obsolete. This means one could be forced out their career at the age of 25 or so (Sparrow 2019). Given our psychology, it seems reasonable to worry that this will have negative effects. But, if post-persons are more psychologically immune, then we may reduce our concern for the psychological well-being of the radically enhanced.
} 
control over their mental states (jealousy, rage, boredom, self-worth), it seems that two things are likely to happen. First, the enhanced cooperators can enter mental states that make them amenable to cooperating at a lower level. Playing Go Fish has its upside when you are playing with children. If post-persons are smarter than mere persons to the degree that mere persons are smarter than non-human animals, it is fair to say that mere persons will be like children in the eyes of the enhanced. As adults we become frustrated with children over extended periods of time, but we lack the capabilities of the enhanced. The enhanced will have the capacity to be far more patient and will be able to sustain cooperation for much longer, as they can mitigate their irritation and boredom. Praise need not be a central motivation of the enhanced. We feel cheated when our accomplishments go unrecognized and are beyond indignant if our accomplishments are credited to someone else. It does not follow that features of our psychology will be predominant features of the enhanced. The enhanced may be far happier that a positive impact is made, rather than receiving credit for it, and if they aren't, they will have the tools to foster this sentiment. They will recognize that mere persons need to cooperate to grow as individuals and put their ideas on the sideline so mere persons can contribute. Second, their superior cognitive powers may give them the ability to more clearly identify errors in ethical and general reasoning. Finally, the enhancements I offered are a narrow window of what the radically enhanced may be like. They may undergo specific moral disposition enhancements. One such method that has been proposed is to "attenuate counter-moral emotions." Such emotions might include aversion to racial groups and impulse toward violent aggression (Douglas 2008, p. 231). If moral disposition enhancement occurs along the way, the enhanced will not experience anything like the out-group hostility that is all too routine in our society. The combination of direct mental state control, increased rationality and specific moral enhancement provide compelling reasons to think the enhanced won't believe they have superior rights and interests to our own.

The second point (enhanced cognitive abilities) needs more attention. In the next section I will argue that enhancing our cognitive abilities can serve as a moral disposition enhancer.

\section{Cognitive enhancement}

One way to think about cognitive enhancements is in terms of raw computing power. The enhanced may become better calculators or better fact accumulators. Cognitive abilities understood in this way aren't terribly interesting, as there already exists great variation in ability, and computers perform many basic tasks for us regularly. The sorts of cognitive enhancements we should aim for are ones that increase our ability to abstract. If the radically enhanced deserve to be called post-persons, they will more readily use abstraction in their reasoning, and quite possibly in a way that is off limits to us. If mere persons are better abstractors, then they will have better 
insight into conflicting propositions. This will result in more coherent views, and increase the probability of solving contemporary moral problems. ${ }^{12,13}$

To illustrate what I have in mind we can focus on wealth inequality, one contemporary problem that currently occupies the public's mind. The ten richest men in the world each have wealth in excess of fifty billion dollars. The top three have more than twice that. Some think this is perfectly appropriate, and even morally good. But what if this vast wealth was not represented by ones and zeros in complex investment mechanisms, or tied up in physical assets like luxury properties and yachts, but rather in raw goods necessary for survival ${ }^{14}$ What if billionaires were explicitly Grinchy?

\subsection{The Grinchy Billionaire}

Imagine a wealthy billionaire shifts his investments from long term assets to physical goods that are necessary to maintain a life worth living. He invests in medicines like insulin and vaccines, while diversifying his portfolio with stores of clean water and durable food products like grains and rice. The Grinchy Billionaire decides to store these goods in the center of towns in developing countries, just out of arms reach of those people who are desperately in need. This billionaire is patient and has taken a long-term investment strategy, waiting for the goods to become scarce, or some other market mechanism to take effect so he can increase profits. Naturally, people will try to steal these goods (as it can mean the difference between life and death), so armed guards will be hired to secure the compound. Does this seem moral?

My intuition is no, but I am not concerned with the conclusion as much as the influence of abstraction on our reasoning. The enhanced will engage in this sort of reasoning automatically and they will compare this case against ten, twenty or a hundred cases to see which intuitions are being pumped, ${ }^{15}$ and which intuitions are worth preserving. This sort of reasoning can help tease apart a mere difference from a moral difference. My own intuition is that the method of storing wealth is a mere, and not a moral difference. So, if you find the Grinchy billionaire morally impermissible, you should think the same of the regular billionaire.

The previous point was to establish the power of abstraction and how it may aide in our ethical and general reasoning. While the thought experiment purported to be about wealth inequality, it is really about enhancement. Buchanan notes the

\footnotetext{
12 Persson and Savulescu (2012) argue that the cause of our problems is our thinking. For example, pollution is a symptom of climate change, but our thinking is the cause. They argue the best way to solve moral problems is to enhance our psychology.

1330 million adults in the US can't read. Twice that number have basic reading skills (Baer et al. 2009). How much different would the world be if the average level was above proficient? At minimum, the level of discourse in the public sphere would be far higher.

14 At the time of this writing the coronavirus pandemic is in a stage of nascent growth. In the U.S. the government response may include paid sick leave, bailouts for business, cash payments to individuals and subsidized health care. All of this requires wealth redistribution. In a trenchant opinion piece Farhad Manjoo highlights how we are all socialists in a pandemic (2020).

15 See Dennett (2013).
} 
inequality already present between developed and developing countries "In fact, we already live in such a world: the world's worst-off people are unenhanced compared with the best off. On average, people in 'developed' countries are taller, stronger, healthier, better able to produce and create more, better able to develop their talents, better able to promote their own values, and longer-lived than people in 'lessdeveloped' countries" (Buchanan 2009, p. 357). Buchanan is talking about the importance of a concept like human rights, and that even though those in developed countries are better off, the concept of human rights tells us we have obligations to provide basic living conditions to those that are less well off. The claim in no way makes reference to notions of superiority or inferiority. If we accept that better diets, access to health care, and education constitute enhancements, then wealthy elites, like the Grinchy Billionaire, can be thought of as post-persons, ${ }^{16}$ and the impoverished can be thought of as mere persons. For those that are concerned with the enhanced edging people out of society, promoting their own interests, they should be equally concerned with the wealthy, who do that now.

A large portion of the opposition to enhancement come from religious conservatives. ${ }^{17} \mathrm{~A}$ full $61 \%$ of adults in the US think there is too much wealth inequality, but only $41 \%$ of conservatives think so. Further, $60 \%$ of conservatives think wealth inequality is driven by life choices (Horrowitz et al. 2020). If I am right that wealth inequality and enhancement are far more alike than not, and conservatives oppose enhancement, but are ok with wealth inequality, then there is a mistake in reasoning happening somewhere. One candidate is in how the scenarios are framed (Thaler and Sunstein 2008, p. 36). The ability to abstract is one tool to overcome pernicious framing effects. More worrying is that only $6 \%$ of conservatives (and $13 \%$ of democrats) think that philosophy and reason are a source of guidance on right and wrong, while $87 \%$ of conservatives think religion and common sense are sufficient guides to morality (Religion in America 2015). This is even reflected in philosophy at the highest level. Kass, a bioconservative who has served on the president's council of bioethics, has famously argued for the wisdom of disgust (Kass 1997). The enhanced will have reason to be skeptical of their primal intuitions and appreciate the role careful thinking plays in creating a moral society. The benefits conferred by increasing our cognitive capacities are unknown, but it is difficult to imagine that better thinkers will make the errors we routinely make.

It might be objected that since I think wealth inequality is impermissible, and since the enhanced are analogous to the Grinchy Billionaire, I should treat the cases equally and argue against enhancement. The analogy falls apart as the Grinchy Billionaire is all too human. I would be against enhancement if the goal was to create better athletes, entertainers and those that can create algorithms to better track the stock market, but these are only a small fraction of the goals of enhancement. If we enhance the things that make humans so wonderful, if we enhance the ability

\footnotetext{
16 The analogy could just as easily be made within affluent states. The prospects and outcome for someone with a PhD in evolutionary biology are much different than that of the local Sasquatch hunter.

17 Kass (2017) offers a conservative catholic viewpoint. Francis Fukuyama (2002) offers a more secularized conservative viewpoint.
} 
for careful reflection, or the ability to exercise compassion, then post-persons won't embody the Grinchy Billionaire.

\section{Moral status and vulnerability}

Our vulnerabilities may be exploited in the form of oppression (Frye 1983), as a way to exclude from political and social life (Mill 1869), or as way to justify differential treatment and instill obedience in women (Wollstonecraft 1792). Vulnerability may vary by group. Not because one group is intrinsically more vulnerable than the next, but because group membership can serve as a way to identify, impose and uphold pernicious societal norms. These norms have forced women to fight for the right to govern their own bodies (Thomson 1971). Same sex couples have to battle for equal treatment, and in the case of gay men, are often thought of as disgusting or viewed as contaminants (Nussbaum 2004, p. 113). The disabled have to argue that their differences are mere differences, as opposed to bad differences (Barnes 2014), and those that suggest that racism, the most visible form of discrimination is still a problem, are met with public backlash (Yancy 2018). As important as these issues are, they fall outside of the scope of this paper. The radically enhanced will be sufficiently different than us, warranting their vulnerability to be thought of as different in kind. Martha Nussbaum captures the idea of vulnerability well.

But the idea of vulnerability is closely connected to the idea of emotion. Emotions are responses to these areas of vulnerability, responses in which we register the damages we have suffered, might suffer, or luckily have failed to suffer. To see this, let us imagine beings who are really invulnerable to suffering, totally self-sufficient... Such beings would have no reason to fear, because nothing that could happen to them would be really bad. They would have no reasons for anger, because none of the damages other people could do to them would be a truly significant damage, touching on matters of profound importance. They would have no reasons for grief, because, being self-sufficient, they would not love anything outside themselves, at least not with the needy human type of love that gives rise to profound loss and depression. Envy and jealousy would similarly be absent from their lives (Nussbaum 2004, p. 6).

Post-persons will not be gods, but they will be much closer than mere persons are. If we lack moral concern for gods, and the reason is their lack of vulnerability, then we have some reason to include vulnerability as a criterion for moral status. Post-persons on my account, will be far less vulnerable, and hence, warrant less moral concern. Vulnerability is a scalar property, one that should be viewed in terms of weak thresholds, of which, adding to, and taking from, make a great difference to moral status.

As alluded to earlier, the difference in vulnerability of mere persons is incidental rather than intrinsic. We are all in the same boat, but in different seas. For example, a refugee will be highly vulnerable, as she might be in a new country, unfamiliar with the language and customs, and looked at as an out-group member. But this is an accident of nature. If the Grinchy Billionaire loses his fortune, and becomes a 
refugee, he will be just as vulnerable as the typical refugee. He is still in the same boat, but in a different sea. Our circumstances change the degree of our vulnerability, but not our vulnerability in kind. The enhanced are much different. They will be in the same sea as us, but in a different boat. The experience of an enhanced refugee will be unlike that of the millions of refugees in desperate need of aid.

To capture our intrinsic invulnerability, absent the baggage of unjust societal norms, I want to focus on our sensitivity to insult and our ability and composure to rebuff them. Southern white men grow up in cultures of honor where they are expected to defend themselves reflexively against insult. Social status is called into questions for those men who aren't "men" and don't exhibit lax talionis-the law of retribution. This behavior is found on and off the farm, as one study found differences in responses to insult among Southern and Northern college students. In this study, participants were bumped into and then insulted (called an asshole) by a researcher. Southern students' levels of cortisol and testosterone increased more so than their Northern counterparts after the bump and insult. Southerners felt that others perceived them as having less social status, and when given an opportunity to demonstrate their toughness by being administered electrical shocks, they opted for higher levels than their Northern counterparts. They were even more likely to exhibit aggressive behavior towards others after the bump and insult (Cohen et al. 1996). White republican men, with a high school education who live in rural areas are most likely to be gun owners and cite protection as the number one reason for ownership ${ }^{18}$ (The Demographics of Gun Ownership 2017). Data from twin studies suggest there is a genetic component to political beliefs (Funk et al. 2013), and FMRI has been used to predict political party affiliation by mere exposure to non-political images (Ahn et al. 2014). While honor culture certainly has a cultural component, it may have a genetic component as well. Are these white men more vulnerable than their northern counterparts? If so, do they deserve more moral status?

The answer to the first question is both yes and no. They have emotional response to insults, that others may readily brush off. They may even be disposed to view mild insults as damaging and elicit an emotional response. Defending your territory and manhood all day is both taxing and dangerous. But this isn't drastically different than our general vulnerability in different contexts. For example, if a northern undergraduate is told her idea is risible in front of the class, she may have a similar physiological and emotional response to those in honor cultures. In the U.S., FERPA laws are in place to ensure education records are kept private, sparing students from the pain and embarrassment of sharing a poor performance. For college students, good grades may serve as a mark of social status, and those that struggle may perceive that others think they have a lower social status. So the vulnerability is different in degree and type, but not in kind. The cultural and genetic lottery will shape

\footnotetext{
18 Women are the least likely to own weapons. This is odd in that women are far more likely to be victims of sexual assault and domestic violence. Given that women are in some instances more vulnerable to physical abuses, you would expect them to own the most guns if gun ownership is really about protection. While gun ownership among white men may be related to protection, I speculate that honor culture and protecting "manhood" play a pivotal role.
} 
what bothers us, and how it does, but we are all still in the same boat, only the context of the seas change. In order for moral status to change, vulnerability along many dimensions must change.

The enhanced will be far less vulnerable along several dimensions, enough to lower their moral status. Insults will not readily bother them (as they don't both many mere persons), and when they do, they will have the capacity to reduce the severity of the blow. They won't be ashamed of poor performance in athletics or academics, because it will be obvious that those that excel in certain areas will have different enhancements. It will be readily apparent that their talents are not entirely their own. It will become far more obvious the degree to which our genetic and technological enhancements supplement character and drive our performances. Post-persons will be less manipulatable. Mere persons love rewards, even for the most trivial of accomplishments, such as the badges and awards ubiquitous in mobile applications. Post-Persons will have control over their dopamine driven reward pathway, allowing them to recoup their time, and focus on things that really matter.

Finally, decreasing vulnerability will make post-persons more moral. Direct mental state control will allow them to exhibit the virtue of courage or allow them to curb the desire to deceive. Following moral rules will become the rule, and not the exception. They will abandon lax-talionis, and focus on ways to improve the quality of life for people in great need, as opposed to creating more pain. ${ }^{19}$ They will be more generous, as they will have the capacity to feel the same excitement towards a traditional lottery ticket, as one whose grand prize is millions of dollars to charity. For the radically enhanced both a single and a million deaths will be a tragedy.

\section{Objections}

Many will still be worried that the enhanced will not be nearly as altruistic as I have argued for. I will concede that nothing necessitates the enhanced to be benevolent beings. But necessity is too high of a bar to set. We set the bar far lower for the sorts of interventions we already employ. Imagine if we thought it necessary for educational interventions to guarantee smarter and more moral citizens before we implemented them. Instead we hope that these sorts of interventions make an on average contribution to the quality of children's lives. On average, we hope they are better able to cope with the demands of contemporary society. The same should be thought of for the radically enhanced. They will be in a far better position to realize errors in reasoning and have the tools to better curb unwanted desires and impulses. But this will be no utopia. As with all

\footnotetext{
19 Katrien Devolder has argued that prisoners have the right to die. She focuses on the case of Frank Van Den Bleeken, a serial rapist and murder. He admits he has done terrible things and feels he is beyond recovery, and yet, is destined to a life of imprisonment (2016). For a brief period of time the court ruled he could be euthanized. One victim's sister remarked "For us this is incomprehensible. He should rot in his cell" (Bletchly and Allen 2014). The court later overturned their ruling, ensuring Bleeken will live. There is a real question as to what sorts of punishments are appropriate, and for how long they should be meted out. If it was up to family members of victims, I fear that the punishment would be indefinite.
} 
populations there will be variation, and there will still be those we need protection from. It will take an enormous effort to figure out the science of improving humanity, but it strains credulity to think this is unachievable or unlikely through enhancement. If you are worried that the enhanced will be worse in some ways than us, consider de-enhancements, the interventions that make us less intelligent and less physically and cognitively capable. Would we be better off? Hesitation in response may be due to a status quo bias (Bostrom and Ord 2006), or an imagined hope that we are the pinnacle of perfection. However, I find it hard to imagine that if we stumbled across human-like beings whose capacities were greater than ours by a mere $5 \%$, that we should encourage them to reduce their capacities to match our own.

What does MSV mean for non-human animals? Surely, they are more vulnerable than us. Do they deserve more moral status? Maybe, but this is an empirical question we are unable to answer at the moment. We have reasons to think non-human animals experience pain like we do. They have similar anatomy and physiology, and their behavior indicates they are capable of pain. But their inner life is probably drastically different. I hesitate to speculate what it is like, but I am comfortable saying that like the enhanced, animals are in a different boat, but this time in the opposite direction. Their inner lives are most likely not anywhere near as rich as ours, and they probably are incapable of feeling some of the deepest senses of sadness and loss that we are. Again, this is an empirical question, and if it turned out they had rich inner lives and are far more susceptible to emotional pains, would it be so bad if we elevated their moral status? It would certainly be weird and uncomfortable to view a dairy cow the same as a human, but that would seem far more preferable than treating them the way we currently do. I think we have little to worry on this front, but time will tell.

Finally, emotional and physical pain is often thought to be a good thing. It helps us grow into mature individuals and prevents us from injuring ourselves to the point of no return. But it is not necessary as evidenced by Jo Cameron, a 71-year-old woman who experiences little anxiety and described childbirth as a tickle (Murphy 2019). I am not suggesting a complete removal of pain, but with the help of technology such as optogenetics we may alter our relationship to it, freeing us from the bondage it keeps us in. There is no reason giving birth needs to be extremely painful, just like there is no reason to fear public speaking. How much pain we do and don't need is an empirical question. If we start enhancing, we can answer this along the way. My optimism may need some bridling, but the alternative is to trust natural selection got it right. I find this as implausible as the hypothesis we were created by an all knowing, all kind, all powerful deity.

Finally, this is a speculative account and should be treated as such. My aim is not to describe how the enhanced will actually be, rather, it is to give a plausible conception of the enhanced and establish that they could have a lower moral status than their ordinary human counterparts, despite increased capacities and abilities. On this front, I think I succeeded. 


\section{Conclusion}

I have argued that it is likely humans will seek out enhancements that allow for greater mental state control. It is readily assumed that enhancement will have the effect of raising moral status, or at minimum, confer some additional rights the unenhanced will lack. As greater mental state control can reduce one's vulnerability, and vulnerability is a criterion for moral status, the enhanced will experience a moral status reduction when compared to their ordinary human counterparts. If I am right about the enhanced it is not their attitudes towards us we should be most afraid of, it is our attitudes toward them.

\section{References}

Ahn, W.-Y., Kishida, K. T., Gu, X., Lohrenz, T., Harvey, A., Alford, J. R, et al. 2014. Nonpolitical images evoke neural predictors of political ideology. Current Biology, 24(22), 2693-2699. https://doi. org/10.1016/j.cub.2014.09.050.

Agar, N. 2014. Truly human enhancement: A philosophical defense of limits. Cambridge: The MIT Press.

Aravanis, A.M., L.-P. Wang, F. Zhang, L.A. Meltzer, M.Z. Mogri, M.B. Schneider, and K. Deisseroth. 2007. An optical neural interface: In vivo control of rodent motor cortex with integrated fiberoptic and optogenetic technology. Journal of Neural Engineering. https://doi.org/10.1088/1741-2560/4/3/ s02.

Baer, J., Kutner, M., \& Sabatini, J. (2009). Basic Reading Skills and the Literacy of America's Least Literate Adults: Results from the 2003 National Assessment of Adult Literacy (NAAL) Supplemental Studies (NCES 2009-481). National Center for Education Statistics, Institute of Education Sciences, U.S. Department of Education.

Barnes, E. 2014. Valuing disability, causing disability. Ethics 125 (1): 88-113. https://doi. org/10.1086/677021.

Bletchly, R., \& Allen, P. 2014. Why should our sister's killer be allowed to die with dignity when our suffering goes on? Mirror. Retrieved from https://www.mirror.co.uk/news/should-sisters-killer-allow ed-die-4278333

Bloom, P. 2018. Against empathy: The case for rational compassion. Londres: Vintage.

Bostrom, N., and T. Ord. 2006. the reversal test: Eliminating status quo bias in applied ethics. Ethics 116 (4): 656-679. https://doi.org/10.1086/505233.

Bostrom, N. 2014. Superintelligence: Paths, dangers, strategies. Oxford: Oxford University Press.

Buchanan, A. 2009. Moral status and human enhancement. Philosophy \& Public Affairs 37 (4): 346-381. https://doi.org/10.1111/j.1088-4963.2009.01166.x.

Clark, A. 2003. Natural-born cyborgs: minds, technologies, and the future of human intelligence. Oxford: Oxford Univ. Press.

Cleary, D.R., A. Ozpinar, A.M. Raslan, and A.L. Ko. 2015. Deep brain stimulation for psychiatric disorders: Where we are now. Neurosurgical Focus. https://doi.org/10.3171/2015.3.focus1546.

Cohen, D., R. Nisbett, B. Bowdle, and N. Schwarz. 1996. Insult, aggression, and the southern culture of honor: An experimental ethnography. Journal of Personality and Social Psychology 70 (5): 945-960.

De-bary, T., and I. Bloom. 2000. Sources of Chinese tradition. New York: Columbia University Press.

Deisseroth, K. 2011. Optogenetics. Nature Methods 8 (1): 26-29. https://doi.org/10.1038/NMETH.F.324.

Dennett, D.C. 2013. Intuition pumps and other tools for thinking. New York: W.W. Norton \& Company.

Devolder, K. 2016. Euthanasia for detainees in Belgium. Cambridge Quarterly of Healthcare Ethics 25 (3): 384-394. https://doi.org/10.1017/s0963180116000037.

Dib-Hajj, S.D., T.R. Cummins, J.A. Black, and S.G. Waxman. 2010. Sodium channels in normal and pathological pain. Annual Review of Neuroscience 33 (1): 325-347. https://doi.org/10.1146/annur ev-neuro-060909-153234. 
Douglas, T. 2008. Moral enhancement. Journal of Applied Philosophy 25 (3): 228-245. https://doi.org/10 .1111/j.1468-5930.2008.00412.x.

Earp, B.D., and J. Savulescu. 2020. Love drugs: The chemical future of relationships. Stanford, CA: Redwood Press.

Empíricus, S. 1996. The skeptic way: sextus empiricuss "Outlines of Pyrrhonism" (B. Mates, Trans.). New York: Oxford University Press.

Frye, M. 1983. Oppression. In A. Cudd and R. Anderson (ed.), Feminist theory: A philosophical anthology. Blackwell Publishing. (2005).

Fukuyama, F. 2002. Our posthuman future: Consequences of the biotechnology revolution. New York: Farrar, Straus and Giroux.

Funk, C.L., K.B. Smith, J.R. Alford, M.V. Hibbing, N.R. Eaton, R.F. Krueger, et al. 2013. Genetic and environmental transmission of political orientations. Political Psychology 34 (6): 805-819. https:// doi.org/10.1111/j.1467-9221.2012.00915.x.

Glover, J. 1999. Humanity: A moral history of the twentieth century. New Haven, CT: Yale University Press.

Harris, J. 1985. Value of life: an introduction to medical ethics. Abingdon: Routledge.

Hochberg, L. R., Serruya, M. D., Friehs, G. M., Mukand, J. A., Saleh, M., Caplan, A. H, et al. (2006). Neuronal ensemble control of prosthetic devices by a human with tetraplegia. Nature, 442(7099), 164-171. https://doi.org/10.1038/nature04970.

Horowitz, J. M., Igielnik, R., \& Kochhar, R. 2020. Most Americans say there is too much economic inequality in the U.S., but fewer than half call it a top priority. Retrieved February 20, 2020, from https ://www.pewsocialtrends.org/2020/01/09/most-americans-say-there-is-too-much-economic-inequ ality-in-the-u-s-but-fewer-than-half-call-it-a-top-priority/

Husi, S. 2017. Why we (almost certainly) are not moral equals. The Journal of Ethics 21 (4): 375-401. https://doi.org/10.1007/s10892-017-9250-4.

Kass, L. 2017. Leading A Worthy Life: finding meaning in modern times. S.1.: Encounter Books.

Kass, L. 1997. The Wisdom of Repugnance. The New Republic, 17-26.

Levy, N. 2007. Neuroethics. Cambridge: Cambridge University Press.

Manjoo, F. 2020. Republicans want medicare for all, but just for this one disease. New York Times, 11 March 2020, www.nytimes.com/2020/03/11/opinion/coronavirus-socialism.html.

Mcfarland, D.J., A.T. Lefkowicz, and J.R. Wolpaw. 1997. Design and operation of an EEG-based braincomputer interface with digital signal processing technology. Behavior Research Methods, Instruments, \& Computers 29 (3): 337-345. https://doi.org/10.3758/bf03200585.

McMahan, J. 2009. Cognitive disability and cognitive enhancement. Metaphilosophy 40 (3-4): 582-605.

Mill, J. (1869). The Subjection of Women. In A. Cudd and R. Anderson (Ed.), Feminist Theory: A Philosophical Anthology. Blackwell Publishing. (2005)

Murphy, H. 2019. At 71, she's never felt pain or anxiety. Now Scientists Know Why. New York Times. Retrieved from https://www.nytimes.com/2019/03/28/health/woman-pain-anxiety.html

Nussbaum, M.C. 2004. Hiding from humanity. Princeton, NJ: Princeton University Press.

Offord, C. 2017. Targeting sodium channels for pain relief. The Scientist Magazine. Retrieved from https ://www.the-scientist.com/features/targeting-sodium-channels-for-pain-relief-30147

Persson, I., and J. Savulescu. 2012. Unfit for the future?: The need for moral enhancement. Oxford: Oxford University Press.

Religion in America: U.S. Religious Data, Demographics and Statistics. 2015. Retrieved from https:// www.pewforum.org/religious-landscape-study/.

Smith, D.L. 2012. Less than human: Why we demean, enslave, and exterminate others. New York: St. Martins Griffin.

Sparrow, R. 2019. Yesterday's child: How gene editing for enhancement will produce obsolescenceand why it matters. The American Journal of Bioethics 19 (7): 6-15. https://doi.org/10.1080/15265 161.2019.1618943.

The Demographics of Gun Ownership. 2017. Pew Research Center, Washington, DC. Retrieved from https://www.pewsocialtrends.org/2017/06/22/the-demographics-of-gun-ownership/

Thaler, R.H., and C.R. Sunstein. 2008. Nudge: Improving decisions using the architecture of choice. New Haven, CT: Yale University Press.

Thomson, J.J. 1971. A defense of abortion. Philosophy \& Public Affairs 1 (1): 47-66.

Wolpaw, J.R., and D.J. Mcfarland. 2004. Control of a two-dimensional movement signal by a noninvasive brain-computer interface in humans. Proceedings of the National Academy of Sciences 101 (51): 17849-17854. https://doi.org/10.1073/pnas.0403504101. 
Wollstonecraft M.(1792). The of the pernicious effects which arise from the unnatural distinctions established in society. In: A Cudd, R. Anderson (eds.) Feminist theory: a philosophical anthology. Abingdon: Blackwell Publishing

Yancy, G. 2018. Backlash: What happens when we talk honestly about racism in America. Lanham: Rowman \& Littlefield.

Publisher's Note Springer Nature remains neutral with regard to jurisdictional claims in published maps and institutional affiliations. 